\title{
Pediatric Bilateral Pheochromocytoma and Experience of Laparoscopic Cortical Sparing Adrenalectomy
}

\author{
(D) Ayça Altıncık1, (1) Samim Özen2, (1) Ahmet Çelik3, (1) Zafer Dökümcü3, (1) Şükran Darcan3, \\ (1) Ayhan $\mathrm{Abacl}^{4}$, (1) Ece Böber4 \\ 1Denizli State Hospital, Clinic of Pediatric Endocrinology, Denizli, Turkey \\ 2Ege University Faculty of Medicine, Department of Pediatric Endocrinology, İzmir, Turkey \\ ${ }^{3}$ Ege University Faculty of Medicine, Department of Pediatric Surgery, İzmir, Turkey \\ ${ }^{4}$ Dokuz Eylül University Faculty of Medicine, Department of Pediatric Endocrinology, İzmir, Turkey
}

\begin{abstract}
Pheochromocytomas are neuroendocrine tumors. In this report, we present a 15-year-old girl who had cerebral palsy and pheochromocytoma. She also had a diagnosis of hyperinsulinemic hypoglycemia in her history. She underwent bilateral laparoscopic cortical sparing adrenalectomy. We report the experience of laparoscopic bilateral cortical sparing adrenalectomy of a pediatric pheochromocytoma.

Keywords: Pheochromocytoma, laparoscopic surgery, paraganglioma
\end{abstract}

\section{Introduction}

Pheochromocytomas and paragangliomas are neuroendocrine tumors arising from the chromaffin cells. The term pheochromocytoma is used for tumors that occur in the adrenal gland whereas paraganglioma is used for those of extra-adrenal origin (1). The estimated incidence of pediatric pheochromocytomas is 1 in 50.000 (2). Although they can occur as sporadic tumors, a hereditary basis of the disease and identification of a germ line mutation is higher in children compared to adults, reported varying between 30-70\%. Von Hippel-Lindau (VHL) disease, multiple endocrine neoplasia (MEN) 2A, 2B and neurofibromatosis (NF) Type I are the most frequently reported syndromes associated with pheochromocytomas. Therefore, genetic testing is imperative for all children who present with pheochromocytoma, regardless of familial history $(1,3)$.

The clinical presentation of childhood pheochromocytoma is highly variable. Symptoms are mostly due to the elevated levels of catecholamines. Sustained hypertension is found in more than $60 \%$ of pediatric pheochromocytoma cases. However, the presence of hypertension is not mandatory, and there is no clear correlation between the levels of catecholamines and symptoms (2). Palpitations, headache, excess sweatiness, anxiety and pallor should arouse suspicion of pheochromocytoma in children. Signs and symptoms of sweating, nausea, vomiting, weight loss, polyuria or visual disturbances may also be presenting symptoms in children $(2,4)$.

\section{Address for Correspondence}

Ayça Altıncık MD, Denizli State Hospital, Clinic of Pediatric Endocrinology, Denizli, Turkey Phone: +90 5337498817 E-mail: aycagate@yahoo.com ORCID ID: orcid.org/0000-0002-4101-9299 Received: 21.04.2017 Accepted: 15.06.2017

${ }^{\circ}$ Copyright 2018 by Ege University Faculty of Medicine, Department of Pediatrics and Ege Children's Foundation The Journal of Pediatric Research, published by Galenos Publishing House. 
Measurement of plasma free metanephrine and normetanephrine or 24-h urinary fractionated metanephrines are considered to be the most accurate biochemical tests for pheochromocytoma (4).

Surgical resection is the treatment of choice and in the setting of bilateral pheochromocytoma, cortical-sparing procedures should be considered (4). Appropriate preoperative medical treatment to block the effects of catecholamines for at least 10-14 days before surgery is mandatory to keep the intraoperative risks minimum. Depending on institutional experience, different protocols have been used to ensure adequate preoperative preparation $(1,2,4)$.

In this article, we report an incidentally diagnosed bilateral pheochromocytoma and aim to highlight the importance of questioning.

\section{Case Report}

A 15-year-old motor-mentally retarded girl was admitted to an outpatient clinic for routine check-up of osteopenia. She had been on calcium gluconate and vitamin D therapy for osteopenia secondary to immobilization. Renal ultrasonography was planned to investigate nephrocalcinosis and a $41 \times 34 \times 47 \mathrm{~mm}$ mass in the right and $49 \times 25 \times 45 \mathrm{~mm}$ mass in the left adrenal gland were identified.

She was born at term after an uneventful pregnancy with a birth weight of $3.200 \mathrm{~g}$. There was a consanguinity between parents. She had a diagnosis of transient hyperinsulinemic hypoglycemia (serum insulin $20 \mathrm{IU} / \mathrm{mL}$, glucose $34 \mathrm{mg} / \mathrm{dL}$ ) during the neonatal and early infancy period and had been on diazoxide therapy. Her parents had ceased administering the drugs of their own choice. The family history was unremarkable regarding pheochromocytoma and/or adrenal mass or hypertension. After further questioning, her mother complained regarding sweating, anxiety and flushing attacks.

On physical examination, her weight was $45 \mathrm{~kg}$ (-1.76 standard deviation score), however, her height was not evaluated properly due to contractures. Her blood pressure was $142 / 88$ ( $99^{\text {th }}$ percentile/adjusted for age and gender, it was 134/88), her heart rate was 72 beats per minute. She had severe increased muscle tone, rigidity and contractures at multiple joints. Further questioning revealed that the patient had had attacks of flushing and diaphoresis since 1 year of age. Ambulatory blood pressure monitoring revealed hypertension. Twenty-four hour urinary metanephrine was $2.761 \mu \mathrm{g} /$ day (normal value: 52-341), normetanephrine was 1.198-7.145 $\mu \mathrm{g} /$ day (normal value: 88-444), vanillymandelic acid was $22 \mathrm{mg} /$ day (normal value: 3.3-6.5), serum aldosterone (supine) was $178 \mathrm{pg} / \mathrm{mL}(\mathrm{n}=20-220)$, serum renin was $83 \mathrm{pg} /$ $\mathrm{mL}(\mathrm{n}=5.41-34.5)$, adrenocorticotropic hormone $(\mathrm{ACTH})$ was $40.60 \mathrm{pg} / \mathrm{mL}$ (normal: 7.20-63.3 pg/mL), DHEA-SO4 was $28.1 \mu \mathrm{g} / \mathrm{dL}$, total testosterone was $0.28 \mathrm{ng} / \mathrm{mL}$, cortisol was $10.4 \mu \mathrm{g} / \mathrm{dL}$.
Contrast enhanced abdominal computed tomography (CT) revealed that the density of masses were 14 and 22 Hounsfield units respectively (Figure 1). An iodine ${ }^{123}$ metaiodobenzylguanidine (I23MIBG) scan revealed an increased uptake at the adrenal glands.

Due to hypertensive episodes (121/85-145/88 $\mathrm{mmHg}$ ) being detected in the preoperative evaluation, the patient was hospitalized and hypertension was stabilized with increasing doses of phenoxybenzamine (final dose: $40 \mathrm{mg}$ / day) under ambulatory blood pressure monitoring 14 days prior to surgery.

On the day of surgery, firstly a laparoscopic transperitoneal partial adrenalectomy was performed for the left adrenal mass (5-6 cm in diameter) with clear borders. Preoperative hypertensive attacks were managed with phenoxybenzamine. In the same session, the patient was re-positioned for the right adrenalectomy and unlike the preoperative CT scan report, 3 other right adrenal masses were detected. Significantly inflammated and stiff masses were resected laparoscopically. Minor bleeding was easily managed with vessel sealing devices. The masses were removed through a laparoscopic endo-bag without complication.

Following bilateral laparoscopic cortical sparing adreneloctomy, the patient remained normotensive. Postoperatively, laboratory examination revealed normal 24-hour urinary metanephrine $(22 \mu \mathrm{g} / \mathrm{dL})$, normetanephrin (538 $\mu \mathrm{g} / \mathrm{dL})$, noradrenalin $(90 \mu \mathrm{g} / \mathrm{dL})$ dopamine $(337 \mu \mathrm{g} / \mathrm{dL})$ and adrenalin $(1.9 \mu \mathrm{g} / \mathrm{dL})$ levels. An I123MIBG scan showed normal uptake. Hydrocortisone treatment, which was started postoperatively, was tapered and then discontinued. Serum cortisol levels were 9.75-2.58 $\mu \mathrm{g} / \mathrm{dL}$, ACTH levels were 96.7$10.3 \mathrm{pg} / \mathrm{mL}$, respectively (08:00 am \& 23:00 pm).

The diagnosis of PHEO was confirmed histologically. Genetic analyses of RET, VHL, ABCC8, KCNJ11, HNF4A genes were examined regarding the history of hyperinsulinemic hypoglycemia and no mutation was detected.

During her follow up, twelve months postoperatively, the patient remained normotensive with normal serum cortisol, ACTH levels $(11.2 \mu \mathrm{g} / \mathrm{dL}$ and $23 \mathrm{pg} / \mathrm{mL})$ and urinary catecholamine levels. Informed consent was taken from family.

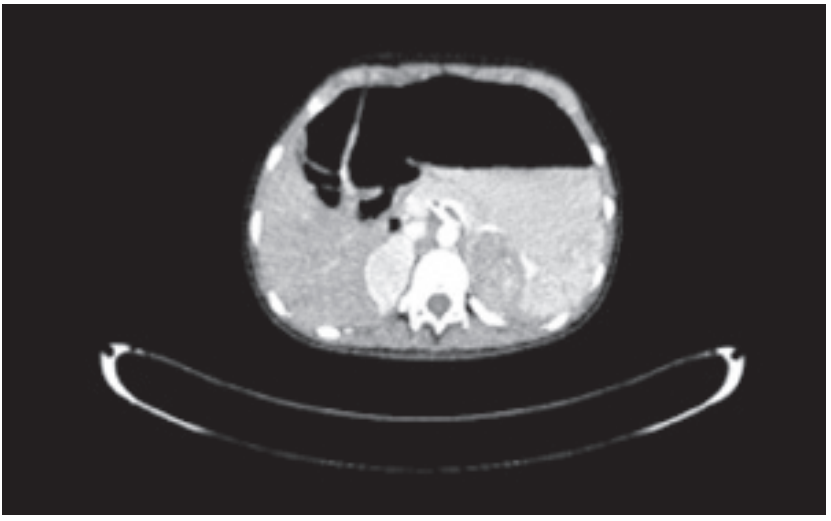

Figure 1. Arterial phase computed tomography of the adrenal masses 


\section{Discussion}

The clinical presentation of pediatric pheochromocytomas is variable ranging from asymptomatic to sudden death. Sustained hypertension has been reported in $60-95.8 \%$ of these patients $(2,4-6)$ The presence of the classical symptom triad (headache, sweating and palpitations) was reported more often in children than adults $(4,6)$. Our case had a typical presentation of the disease, however, regarding her mental retardation; these symptoms (sweating, palpitations and anxiety) were realized belatedly via further questioning.

Measurements of plasma and/or urinary metanephrines, normetanephrines are the most reliable tests for a biochemical diagnosis with almost $100 \%$ sensitivity. An elevation of these analyses 4-fold above the reference range is associated with high probability of tumor $(2,4-6)$. Our case had a diagnostic elevation of urinary metanephrines and normetanephrines.

The initial test of choice for tumor location is magnetic resonance imaging or $\mathrm{CT}$ which have similar diagnostic sensitivities. For functional testing, I123MIBG scintigraphy is a highly specific test that confirms the catecholaminesecreting nature of the tumors and it can locate tumors not seen with cross-sectional imaging (2).

Approximately $59 \%$ of sporadic pheochromocytomas or paragangliomas which are diagnosed in children of $<18$ years old and up to $70 \%$ of those that are diagnosed in children of $<10$ years old are associated with germline mutations (7). Commonly linked syndromes are VHL, MEN 2A/2B (RET gene), NF1 and paraganglioma syndromes (SDHD, SDHC, $\mathrm{SDHB}$ genes). The critical role of $\mathrm{VHL}$ gene for $\mathrm{\nabla}$-cell function has been reported before. There have been a few mice studies regarding VHL gene deletion and severe hypoglycemia. These studies reported that deletion of $\mathrm{VHL}$ gene in the pancreatic $\checkmark$ cells caused postnatal lethal hypoglycemia. However, the hypoglycemic state was neither due to impaired insulin secretion nor insulin receptor hypersensitivity (8-10). In this respect, we examined $\mathrm{VHL}$ and $\mathrm{ABCC} 8, \mathrm{KCNJ11}$, HNF4A genes in our case, however, no mutation was detected. To the best of our knowledge, pheochromocytoma accompanying transient hyperinsulinemic hypoglycemia has not been reported before. This might be a coincidence, however further genetic analyses such as paraganglioma syndromes are needed before accepting this state as coincidence.

Cortical sparing adrenalectomy is preferred in patients with bilateral disease to avoid life-long glucocorticoid deficiency $(2,4,6)$. Both open and laparoscopic approaches have been employed depending on the surgeon's experience. Our case had an uneventful and successful laparoscopic transperitoneal cortical sparing surgery and post-operative cortisol levels remained normal at follow-up.

As a conclusion, a genetic analysis is suggested in all pediatric pheochromocytomas regardless of family history and cortical sparing adrenalectomy should be the choice of preference in bilateral cases. This minimal invasive technique for cortical sparing surgery is also efficient and safe in these patients.

\section{Ethics}

Informed Consent: Consent was taken from family. Peer-review: Externally peer-reviewed.

\section{Authorship Contributions}

Surgical and medical Practices: A.A., S.Ö., A.Ç., Z.D., Ş.D., A.Ab., E.B., Concept: A.A., Design: A.A., Data Collection or Processing: A.A., S.Ö., A.Ab., Analysis or Interpretation: A.A., S.Ö., A.Ab., Literarture Search: A.A., Writing: A.A., S.Ö.

Conflict of interest: No conflict of interest was declared by the authors.

Financial Disclosure: The authors declared that this study received no financial support.

\section{References}

1. Ein SH, Pullerits I, Creighton R, Balfe JW. Pediatric pheochroocytoma. A 36-year review. Pediatr Surg Int 1997;12:595-8

2. Waguespack SG, Rich T, Grubbs E, et al. A current review of the etiology, diagnosis and treatment of pediatric pheochromocytoma and paraganglioma. I Clin Endocrinol Metab 2010;95:2023-37.

3. Martins R, Bugalho MJ. Paragangliomas/Pheochromocytomas: Clinically oriented genetic testing. Int / Endocrinol 2014;2014:794187.

4. Havekes B, Romijn JA, Eisenhofer G, Adams K, Pacak K. Update on pediatric pheochromocytoma. Pediatr Nephrol 2009;24:94350 .

5. Choat H, Derrevere K, Knight L, Brown W, Mack EH. SDHBassociated Paraganglioma in a pediatric patient and literature review on hereditary pheochromocytoma-paraganglioma syndromes. Case Rep Endocrinol 2014;2014:502734.

6. Mishra A, Mehrotra PK, Agarwal G, Agarwal A, Mishra SK. Pediatric and adolescent pheochromocytoma: Clinical presentation and outcome of surgery. Indian Pediatr 2014;51:299-302.

7. Neumann HP, Bausch B, McWhinney SR, et al. Germ-line mutations in nonsyndromic pheochromocytoma. N Engl J med 2002;346:1459-66.

8. Puri S, Cano DA, Hebro M. A role for von Hippel-Lindau protein in pancreatic B cell function. Diabetes 2009;58:433-41.

9. Puri S, Garcia Nunez A, Hebrok M, Cano DA. Elimination of Von Hippel-Lindau function perturbs pancreas endocrine homeostatis in mice. PLoS ONE 2013;8:72213.

10. Kurabayashi A, Kakinuma Y, Morita T, Inoue K, Sato T, Furihata $M$. Conditional VHL gene deletion causes hypoglycemic death associated with disproportionately increased glucose uptake by hepatocytes through an upregulated IGF-1 receptor. PLoS ONE 2013;8:69139. 